\title{
Fertility response of lactating dairy cows subjected to three different breeding programs under subtropical conditions
}

\author{
Abdeltawab Abdelrazek Yassin Khalil[1]
}

\begin{abstract}
Background: It is comprehensively recognized that reduced reproductive efficiency represents a great economic loss to dairy producers. Ovarian cysts and anestrus syndromes are considered the greatest significant causes of low reproductive efficiency in dairy herds worldwide as they detrimentally affect the longevity and profitability of dairy herd. Pregnancy rate is the best available single deciding parameter used for assessment of the reproductive efficiency at the herd level which measures the probability that open cows become pregnant per unit of time. So, the current study was planned to evaluate the suitability of using Ovsynch plus CIDR and G6G resynchronization protocols as an efficient treatment regimen for cystic ovarian diseased cows and anestrus cows, respectively, through comparing pregnancy rates of cystic ovarian diseased cows that subjected to Ovsynch supplemented with controlled internal drug release device with the pregnancy rate of healthy cows that subjected to a Presynch-Ovsynch synchronization protocol, as well as through comparing pregnancy rates of anestrus cows that subjected to G6G treatment protocol with the pregnancy rate of healthy cows. Moreover, possible factors such as breed, parity, and season which may affect the treatment success were also evaluated.

Results: The results of the current study revealed an overall mean pregnancy rate of $36.64 \%$. Moreover, Simmental cows recorded a greater $(p<0.01)$ pregnancy rate $(45.16 \%)$ than that recorded for Holstein cows $(34.98 \%)$ ). A highly significant seasonal effect was observed, as a higher $(p<0.01)$ pregnancy rate was recorded for cows inseminated during cold months (39.54\%) compared with that recorded for cows inseminated during hot months (29.18\%).

Conclusions: No significant differences were detected in the pregnancy rates among the three breeding programs; thence, the application of the G6G synchronization protocol for anestrus cows and Ovsynch-CIDR synchronization protocol for cows with ovarian cysts could be used as effective treatment regimens as they resulted in nearly the same pregnancy rates that recorded for healthy cows. In addition, the treatment response was highly influenced by cow's breed, parity, and season of breeding.
\end{abstract}

Keywords: Dairy Cow, Breeding, Synchronization, Resynchronization, Ovsynch, Presynch

\section{Background}

Maximizing the reproductive efficiency of dairy cows is fundamental to dairy producers because it has a major effect on dairy farm profitability $[28,30]$. Economically, dairy cows must calve regularly at every 12 to 13 months interval. Prolonged inter-calving interval due to delay in the onset of postpartum ovarian recyclicity is considered responsible for reduced reproductive efficiency and

Correspondence: abdeltawab.yaseeen@vet.bsu.edu.eg; yassyn999@yahoo.com

Theriogenology Department, Faculty of Veterinary Medicine, Beni-Suef University, 62511 Beni-Suef, Egypt

\section{Springer Open}

consequently causes economic loss to the dairy producers $[10,17]$. In the last few decades, increased incidence of anovulation and decreased insemination submission rate resulted in lowered reproductive effectiveness of dairy cows and consequently necessitated the application of reproductive programs. Since about $70 \%$ of cows may fail to become pregnant after the first insemination; maximizing pregnancy rate [32] and reducing the inter-services interval $[28,29]$ stay as major objectives of the reproductive regimen preference [28]. A crucial portion of such reproductive management techniques for herds that experience the issues described above is the subjection of 
cows to synchronization programs that permit application of FTAI. The application of these controlled breeding programs leads to reduced intervals from calving to first postpartum services, reduced days open (DO), and consequently reduced the calving interval [44]. The most widespread FTAI protocol is Ovsynch [61]. Studies on dairy cattle [45] showed that the optimum stage to begin the Ovsynch treatment is from day 5 to day 12 of the estrous cycle. Moreover, it has been proposed that the ideal time to begin Ovsynch is at least 10 and no more than 12 days after Presynch [16]. Based on this concept, it has been stated that Presynch with two PGF2 $\alpha$ injections 14 days apart enhanced pregnancy outcomes in cows when Ovsynch was started 12 days after the second PGF2 $\alpha$ injection [22]. Therefore, presynchronization protocols were performed to augment the proportion of cows in early diestrus stage at the first $\mathrm{GnRH}$ dose of the Ovsynch protocol to attain high conception rate (CR) [65]. In this aspect, PO is one of the most widespread protocols used to synchronize ovulation for the first artificial insemination (AI) services postpartum in dairy cows [23]. The main restriction of the PO protocol is the failure to enhance pregnancy in subfertile cows [13] that are predominant in high-yielding dairy cows at the end of the voluntary waiting period [7]. Recently presynchronization protocols including GnRH and PGF2 $\alpha$ were introduced to cope with the restriction of PGF2 $\alpha$-based protocols in anovular cows [61]. These programs improved pregnancy outcomes in anovular cows and emphasized that a high percentage of cows were at the ideal phase of the estrous cycle when the Ovsynch protocol was commenced. G6G begins with administration of PGF $\alpha$, which is designed to induce luteolysis of mature corpora lutea. Two days later, a GnRH injection was intended to induce ovulation. Altogether, the two injections of GnRH are aimed to start a new estrous cycle. Ovsynch is planned to begin 6 days later when the cows are at day 6 of the new induced estrous cycle and are very strong to have a mature preovulatory follicle, eligible to ovulate in response to the first Ovsynch GnRH dose [9]. The use of alternative synchronization of ovulation protocols that optimize the physiological ambience before TAI through the reduced duration of the period of ovulatory follicle dominance [55] and exogenous progesterone supplementation [11] may be a viable strategy to improve PR. In this respect, initiating the synchronization protocol either before or after nonpregnancy diagnosis is a prevalent strategy used to resynchronize estrus for FTAI in lactating cows [25]. Inclusion of CIDR in the synchronization protocols [16] prevented the onset of premature estrus through suppressing ovulation [38], and a normal CL was formed following CIDR removal [63], that way permitting $100 \%$ submission rate for FTAI [53]. Moreover, it has been stated that vaginal insertion of the CIDR for 7 days with an injection of
PGF2 $\alpha$ either 1 day before [43] or at CIDR removal resulted in an increased percentage of cattle in estrus as well as improved CR following FTAI [22]. An additional advantage of the CIDR is that it can encourage estrus in anestrus cattle in early lactation [14]. Lucy et al. [43] declared that CIDR initiates estrus in about $40 \%$ of the anestrus cows and prepubertal heifers. Our hypothesis was that application of the G6G and CIDR synch protocols could improve the PR in acyclic cows which failed to express estrus or failed to conceive after using a PO protocol as well as in cows which suffered from cystic ovarian disease to reach or exceed PR that was recorded for a PO protocol. Thus, the main purpose of the present study was to compare pregnancy outcomes after using three selected breeding programs (PO, G6G, and CIDR-Ovsynch). In addition, the effects of cow's breed and insemination season on the fertility response of the cows to these synchronization protocols were also investigated.

\section{Material and methods}

\subsection{Cows, housing, and feeding}

This retrospective study was accomplished at a commercial dairy farm in Northwestern Egypt. Dairy cows $(n=1520$, 1272 purebred Holstein and 248 purebred Simmental) were included in the current study. Cows were reared up in a free sand-bedded stall equipped with sprinklers and fans for evaporative cooling during summer months. The cows had unrestricted access to freshwater. The animals were fed twice daily a totally mixed ration (TMR) to meet or exceed the minimum nutrient recommendations for lactating dairy cows [49]. Cows were milked thrice daily at $8 \mathrm{~h}$ intervals. The cows were under complete veterinary superintendence. Cows diagnosed with pathological reproductive puerperal conditions (adhesions, abscesses, dystocia, retained fetal membranes, endometritis, purulent vaginal discharge, and ketonuria) were precluded from this study. All AI services were done from 1 January 2017 to 30 April 2018.

\subsection{Breeding programs}

Every week, cohorts of cows that reached $44 \pm 3$ DIM were automatically enrolled in the study by the on-farm dairy management software (Dairy COMP $305^{\circ}$, Valley Ag, Tulare, CA) through a command that randomly assigned a treatment code to every cow. Eligible cows were obligatorily submitted to PO. Cows detected in estrus after an obligatory voluntary waiting period (50 DIM) based on chalk removal and visual observation were inseminated by professional AI technicians according to the a.m/p.m role and did not receive any further treatment. Whereas, cows not detected in estrus within 12 days after the second PGF2 $\alpha$ injection, were assigned for Ovsynch protocol. A total of 1520 cows received TAI and involved in the statistical analysis of the current trial; of them, 481 cows completed the PO breeding 
protocol. Cows diagnosed as non-pregnant ( $35 \pm 3$ days post-last insemination) either after standing heat or after PO were sectioned into two groups. The first group ( $n=665)$ were subjected to G6G breeding program, while the second group $(n=374)$ included cows which experienced cystic ovarian degeneration, and submitted to CIDR-Ovsynch breeding program.

\subsubsection{Presynch-Ovsynch (PO) breeding program}

This group included 481 cows (394 purebred Holstein and 87 purebred Simmental) and were enrolled in this protocol as previously described [46]. Briefly, the cows received two doses of synthetic PGF2 $\alpha$ (500 $\mu \mathrm{g}$ cloprostenol sodium; $2 \mathrm{ml}$ Estrumate; MSD, USA) with 14 days interval on 44 DIM and 58 DIM. The Ovsynch was initiated 12 days later (at 70 DIM) by injection of $12 \mu \mathrm{g}$ GnRH (Buserelin; $3 \mathrm{ml}$; Receptal ${ }^{\circ}$; MSD, USA) followed by injection of synthetic PGF2 $\alpha(500 \mu \mathrm{g}$ cloprostenol sodium; 2 ml Estrumate ${ }^{\circ}$ MSD, USA) 7 days later (i.e., at 77 DIM). Fifty-six hours later, cows received the second GnRH dose (i.e., at 79 DIM). After that, cows were predetermined FTAI at 16 to $18 \mathrm{~h}$ post-second $\mathrm{GnRH}$ injection (i.e., at $80 \pm 3$ DIM) as depicted in Fig. 1.

\subsubsection{G6G breeding program}

In this treatment, 665 cows (567 purebred Holstein and 98 purebred Simmental) were assigned to the G6G synchronization program according to Bello et al. [9]. Briefly, the G6G synchronization protocol is composed of a series of two hormonal treatments that precede the Ovsynch protocol. It begins with an administration of synthetic PGF2 $\alpha$ (500 $\mu \mathrm{g}$ cloprostenol sodium; $2 \mathrm{ml}$ Estrumate; MSD, USA) (day 0) pursued by GnRH administration after 2 days (i.e., day 2). Ovsynch is started after 6 days, as cows received $12 \mu \mathrm{g} \mathrm{GnRH}$ (Buserelin; 3 $\mathrm{ml}$; Receptal ${ }^{\circ}$; MSD, USA) (i.e., day 8 ), followed by an injection of PGF2 $\alpha(500 \mu \mathrm{g}$ cloprostenol sodium; $2 \mathrm{ml}$ Estrumate; MSD, USA) after 7 days (i.e., day 15) and a second injection of GnRH $56 \mathrm{~h}$ after PGF $\alpha$ (i.e., day 17). Cows have received FTAI 16-18 h post-second GnRH treatment (i.e., day 18) as presented in Fig. 2.

\subsubsection{CIDR-Ovsynch TAl breeding program.}

This protocol comprised 374 cows (311 purebred Holstein and 63 purebred Simmental) and were submitted to the CIDR-Ovsynch synchronization program. The cows in this program received a CIDR device including $1.38 \mathrm{~g}$ of progesterone (Eazi-Breed ${ }^{\mathrm{tw}} \mathrm{CIDR}^{\circ}$ insert, Pfizer Animal Health) received via intravaginal insertion together with an injection of $12 \mu \mathrm{g} \mathrm{GnRH}$ (Buserelin; 3 $\mathrm{ml}$; Receptal ${ }^{\circ}$; MSD, USA) (day 0). After 6 days, cows received $500 \mu \mathrm{g}$ cloprostenol ( $2 \mathrm{ml}$ Estrumate; MSD, USA) 1 day (i.e. day 6) before CIDR removal on day 7; after 56 hours, cows received $12 \mu \mathrm{g}$ GnRH (Buserelin; $3 \mathrm{ml}$; Receptal $^{\circ}$; MSD, USA) (i.e., day 9) and were inseminated (FTAI ) after 16-18 h (i.e., day 10) as shown in Fig. 3.

\subsection{Insemination and pregnancy diagnosis}

Frozen semen straws from sixteen proven AI sires were used randomly during the current study, and the straws were distributed homogenously among the three groups to avoid possible sire effects. All TAI services were performed by five well-trained technicians throughout the trial. Pregnancy determination was accomplished on $35 \pm 3$ days post-insemination for all cows using ultrasound provided with a $7.5-\mathrm{MHz}$ transrectal transducer (Easi-Scan; BCF Technology, Rochester, MN, USA). Cows diagnosed as pregnant were reexamined after 60 days post-insemination to emphasize pregnancy.

\subsection{Statistical analyses}

Treatment interactions among season, breed, and breeding protocols and their effects on pregnancy rate were analyzed through general linear model, univariate analysis using SPSS statistical software (IBM, SPSS v25). Significance was considered at $p$ less than 0.05 while a $p$ value more than 0.05 and less than 0.1 was considered a tendency. The data was expressed as mean \pm SEM.

\section{Results}

Regardless of the effects of season of insemination, breed of the cow, and breeding program, the overall mean PR obtained in the present investigation was 36.64\%. Moreover, the mean PR recorded for Simmental cows

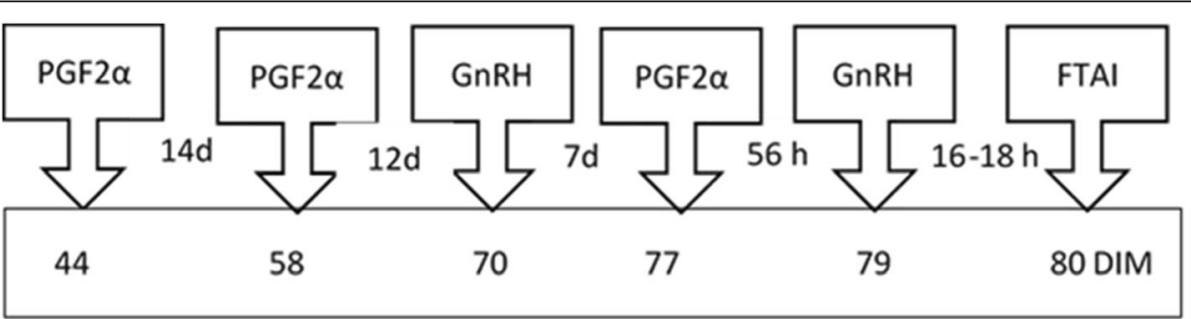

Fig. 1 Schematic representation of the Presynch-Ovsynch breeding program. (PGF2a, prostaglandin F2 alpha; GnRH, gonadotropin releasing hormone; FTAl, fixed-time artificial insemination; DIM, days in milk) 


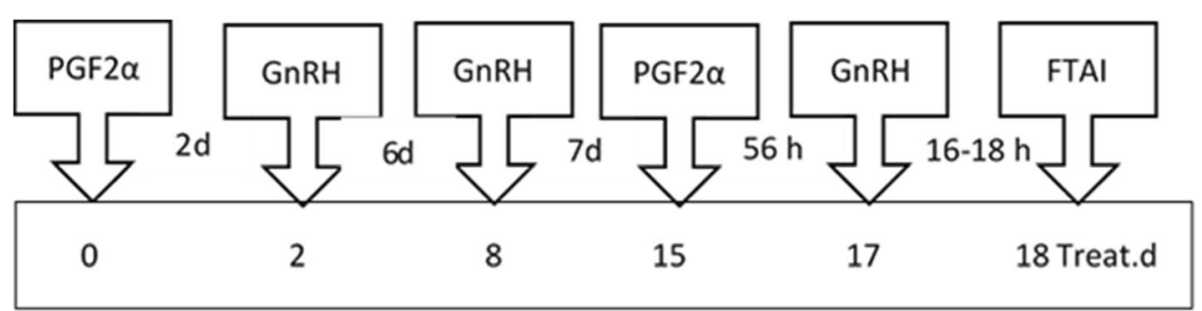

Fig. 2 Schematic representation of the G6G breeding program. (PGF2a, prostaglandin F2 alpha; GnRH, gonadotropin releasing hormone; FTAl, fixed-time artificial insemination; Treat. d, treatment days)

(45.16\%) was greater $(p<0.01)$ than that recorded for Holstein cows (34.98\%) as shown in Tables 1 and 2 . Concerning the seasonal effect on the PR, the current study showed a highly significant seasonal effect $(p=$ 0.000 ) with a higher $\mathrm{PR}$ recorded for cows bred during the cold season (39.54\%) as compared with that recorded for cows bred during the hot season (29.18\%) as depicted in Tables 1 and 2. During the cold season, the response of Simmental cows to PO (56.90\%) and G6G (54.41\%) was significantly $(p<0.01)$ greater than that of Holstein herdmates (36.50\% and $38.10 \%$, respectively).

This effect has not been observed during the hot season. As presented in Tables 1 and 2, the current study revealed no significant $(p=0.608)$ effects of the breeding programs on the PR, regardless of the effect of both cow's breed and season of insemination. The cow's breed by the breeding program interaction tended $(p=0.059)$ to exert an effect on the PR of lactating dairy cows as displayed in Table 1.

Simmental cows responded better achieving higher $(p<0.05)$ PR $(56.9 \%$ and $54.41 \%)$ than that achieved by Holstein cows $(28.33 \%$ and $28.57 \%)$ submitted either to PO or G6G breeding protocols, respectively, during the cold season. However, there was no significant difference in pregnancy outcomes between Holstein cows (37.45\%) and Simmental cows (38.18\%) submitted to CIDROvsynch breeding program during the cold season. Meanwhile, no significant influence of cow's breed by breeding programs interaction was observed on pregnancy results following insemination carried out during the hot months. Within each breed and regardless of the effect of season, similar percentages of pregnancy outcomes after FTAI were obtained for the three breeding programs in both Holstein and Simmental cows (Table 2).

\section{Discussion}

The main objective of this research was to establish that a combination of more than one synchronization protocol is more effective in the amelioration of fertility in cyclic and acyclic as well as in cystic ovarian diseased cows in modern dairy farming. Furthermore, this study could permit a better understanding of fertility-limiting factors in dairy cows reared in commercial dairy farms under subtropical conditions and may let the development of a suitable breeding program to enhance the reproductive efficiency. Accordingly, this research analyzed the effect of both cow's breed and breeding season on pregnancy outcomes in commercial dairy farms.

The overall mean PR obtained in the current study (36.64\%) was on equal terms or superior to that reported earlier (32.2\% and 36.1\%) by Schefers et al. [56]. Nearly the same results were obtained by Dirandeh et al. [19] who recorded PR of $32.7 \%$ and $31.1 \%$ in multiparous lactating Holstein cows reared in Iran and subjected to G7G and double Ovsynch, respectively.

The PO program used in this study consists of two PGF2 $\alpha$ doses given at 14-day interval, with Ovsynch beginning 12 days after the second PGF2 $\alpha$. This program has produced good synchrony of the estrous cycle alongside good fertility at first postpartum inseminations $[27,46]$; therefore, it is currently the commercial dairy

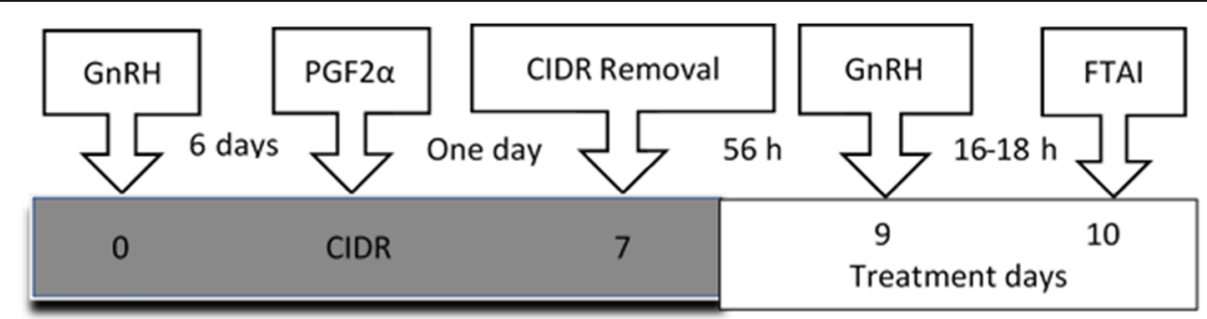

Fig. 3 Schematic representation of the CIDR-Ovsynch breeding program. CIDR, controlled internal drug release; (PGF2a, prostaglandin F2 alpha; $\mathrm{GnRH}$, gonadotropin releasing hormone; FTAl, fixed-time artificial insemination) 
Table 1 Interactions between the tested variables and its effects on the pregnancy rate in dairy cows

\begin{tabular}{|c|c|c|c|c|c|}
\hline \multicolumn{6}{|c|}{ Analysis of between topic effects (DV: Dependant Variable) } \\
\hline Source & Sum of squares & df & Mean square & $F$ value & $p$ value \\
\hline Corrected model & $74,447.514 a$ & 11 & 6767.956 & 2.954 & .001 \\
\hline Intercept & $2,041,111.842$ & 1 & $2,041,111.842$ & 891.026 & .000 \\
\hline Season of insemination & $32,904.704$ & 1 & $32,904.704$ & 14.364 & .000 \\
\hline Breed of the cow & $21,005.374$ & 1 & $21,005.374$ & 9.170 & .003 \\
\hline Synchronization protocol & 2280.659 & 2 & 1140.330 & .498 & .608 \\
\hline Season $\times$ breed & 4165.543 & 1 & 4165.543 & 1.818 & .178 \\
\hline Season $\times$ synch protocol & 36.990 & 2 & 18.495 & .008 & .992 \\
\hline Breed $\times$ synch protocol & $13,019.605$ & 2 & 6509.803 & 2.842 & .059 \\
\hline Season $\times$ breed $\times$ synch protocol & 1034.638 & 2 & 517.319 & .226 & .798 \\
\hline Error & $3,454,440.644$ & 1508 & 2290.743 & & \\
\hline Total & $5,570,000.000$ & 1520 & & & \\
\hline Corrected Total & $3,528,888.158$ & 1519 & & & \\
\hline \multicolumn{6}{|c|}{$R$ squared $=.021$ (Adjusted $R$ Squared $=.014)$} \\
\hline
\end{tabular}

industry standard breeding program for first TAI in Egypt. No significant $(p=0.608)$ differences were detected in the fertility response among the cow groups subjected to the three tested synchronization protocols regardless of the influence of cow's breed and season of insemination (Table 2). Moreover, lactating Holstein cows submitted to PO breeding program recorded an overall PR of $34.01 \%$ regardless the season of insemination (Table 2), while they achieved a PR of $36.50 \%$ when inseminated in cold months (Table 3). These results nearly came in agreement with previous results recorded by Silva et al. [59] and Giordano et al. [31] who recorded a PR of $37 \%$.and $36.3 \%$, respectively, for Holstein cows which received PO synchronization protocol. But our findings were lower than that recorded previously for Holstein cows which received PO synchronization programs by many authors [18], and Fricke et al. [25] recorded a PR of $41.0 \%$. Meanwhile, the results of the last two studies came in agreement with our results observed for lactating Simmental cows which received the PO breeding protocol despite breeding season $(48.28 \%$, Table 2$)$ or inseminated in cold months (56.9\%, Table 3). Further studies are desired to fully clarify these contradictions and completely illustrate the fertility variations reported in these studies.

The great success of GnRH synchronization programs is quite associated with the estrous day at which the program is initiated [18], ovulatory response to the first and second GnRH treatments [9], progesterone concentration during follicular development before insemination [20], and follicular size at the second GnRH injection [48]. The response of ovulation to the first GnRH dose of Ovsynch is highly associated positively with pregnancy rate $[18,26]$, as ovulation to the first GnRH leads to the initiation of a new wave of follicles circa $36 \mathrm{~h}$ later assuring the synchronous development of a healthy

Table 2 Distribution and descriptive statistics of the cows included in this study

\begin{tabular}{|c|c|c|c|c|c|c|c|c|c|c|}
\hline \multirow[t]{3}{*}{ Item } & & \multicolumn{6}{|l|}{ Breed } & \multirow{2}{*}{\multicolumn{3}{|c|}{ Total }} \\
\hline & & \multicolumn{3}{|c|}{ Holstein } & \multicolumn{3}{|c|}{ Simmental } & & & \\
\hline & & $\mathrm{Al}(n)$ & Preg. (n) & PR (\%) & Al. $(n)$ & Preg. $(n)$ & PR (\%) & Al. $(n)$ & Preg. $(n)$ & PR (\%) \\
\hline \multirow[t]{3}{*}{ Season } & Cold & 914 & 342 & $37.42 \pm 1.60$ & 181 & 91 & $50.28 \pm 3.73$ & 1095 & 433 & $39.54 \pm 1.48$ \\
\hline & Hot & 358 & 103 & $28.77 \pm 2.39$ & 67 & 21 & $31.34 \pm 5.71$ & 425 & 124 & $29.18 \pm 2.20$ \\
\hline & Total & 1272 & 445 & $34.98 \pm 1.38$ & 248 & 112 & $45.16 \pm 3.17$ & 1520 & 557 & $36.64 \pm 1.24$ \\
\hline \multirow[t]{4}{*}{ Breeding protocol } & $\mathrm{PO}$ & 394 & 134 & $34.01 \pm 2.39$ & 87 & 42 & $48.28 \pm 5.39$ & 481 & 176 & $36.59 \pm 2.20$ \\
\hline & G6G & 567 & 196 & $34.57 \pm 1.20$ & 98 & 48 & $48.98 \pm 5.07$ & 665 & 244 & $36.69 \pm 1.87$ \\
\hline & CIDR & 311 & 115 & $36.98 \pm 2.74$ & 63 & 22 & $34.92 \pm 6.05$ & 374 & 137 & $36.63 \pm 2.49$ \\
\hline & Total & 1272 & 445 & $34.98 \pm 1.38$ & 248 & 112 & $45.16 \pm 3.17$ & 1520 & 557 & $36.64 \pm 1.24$ \\
\hline
\end{tabular}

$A /$ artificial insemination, Preg. pregnant, $P R$ pregnancy rate, $P O$ Presynch-Ovsynch protocol, CIDR controlled internal drug release, G6G gonadotropin of Presynch, 6 days later gonadotropin of Ovsynch 
Table 3 Effect of interactions among season, breed, and breeding program on pregnancy rate in lactating dairy cows

\begin{tabular}{|c|c|c|c|c|c|c|}
\hline \multicolumn{7}{|c|}{ Season $\times$ breed $\times$ synch protocol } \\
\hline \multicolumn{7}{|c|}{ Dependent variable: pregnancy rate } \\
\hline \multirow[t]{2}{*}{ Season } & \multirow[t]{2}{*}{ Breed } & \multirow{2}{*}{$\begin{array}{l}\text { Breeding } \\
\text { protocol }\end{array}$} & \multirow[t]{2}{*}{ Mean } & \multirow[t]{2}{*}{ SE } & \multicolumn{2}{|c|}{$95 \%$ confidence interval } \\
\hline & & & & & Lower value & Upper value \\
\hline \multirow[t]{6}{*}{$\overline{C o l d}$} & Holstein & $\mathrm{PO}$ & $36.50^{b}$ & 2.90 & 30.82 & 42.17 \\
\hline & & G6G & $38.10^{b}$ & 2.53 & 33.13 & 43.06 \\
\hline & & CIDR & $37.45^{b}$ & 2.84 & 31.87 & 43.04 \\
\hline & Simmental & $\mathrm{PO}$ & $56.90^{\mathrm{a}}$ & 6.28 & 44.57 & 69.22 \\
\hline & & G6G & $54.41^{\mathrm{a}}$ & 5.80 & 43.03 & 65.80 \\
\hline & & CIDR & $38.18^{b}$ & 6.45 & 25.52 & 50.84 \\
\hline \multirow[t]{6}{*}{ Hot } & Holstein & $\mathrm{PO}$ & $28.33^{b}$ & 4.37 & 19.76 & 36.90 \\
\hline & & G6G & $28.57^{b}$ & 3.30 & 22.09 & 35.05 \\
\hline & & CIDR & $32.14^{\mathrm{b}}$ & 9.04 & 14.40 & 49.88 \\
\hline & Simmental & $\mathrm{PO}$ & $31.03^{b}$ & 8.89 & 13.60 & 48.47 \\
\hline & & G6G & $36.67^{b}$ & 8.74 & 19.53 & 53.81 \\
\hline & & CIDR & $27.50^{b}$ & 7.92 & 12.31 & 42.69 \\
\hline
\end{tabular}

PO Presynch-Ovsynch protocol, CIDR controlled internal drug release, G6G gonadotropin of Presynch, 6 days later Gonadotropin of Ovsynch. Values with different superscript letters are significantly different $(p<0.05)$

preovulatory follicle $[9,35]$. Another contribution to an elevated PR is the result of a more functional healthy uterus. The first two doses of PGF $2 \alpha$ have a recovery effect, on the uterus.

Progesterone is considered a master hormone of reproduction, and inadequate progesterone is a principle cause of lowered fertility in high yielder cows. CIDR intravaginal inserts have been used to improve both synchronization and pregnancy rates in FTAI protocols [42]. We ascertained if the integration of a CIDR into the first 7 days of the Ovsynch protocol is effective in treating cystic ovarian disease (COD) cows and achieving a normal or exceed the pregnancy rate recorded for normal healthy cows. Holstein cows which experienced COD responded better to CIDR-Ovsynch protocol (32.14\%) compared with Simmental cows diagnosed with COD and received the same protocol (27.50\%) during the hot season. Meanwhile, during the cold season, the Simmental (38.18\%) and Holstein (37.45\%) cows which experienced COD had shown the same fertility response level when subjected to CIDR-Ovsynch protocol (Table 3). It is interesting to note that the PR obtained for cows which received the CIDROvsynch was the same (36.6\%) as achieved by healthy cows in the PO groups (Table 2). In our study, the cows in the CIDR-Ovsynch group were diagnosed as non-pregnant after previous insemination (i.e., resynchronized). Consequently, our findings confirmed that supplementing cows with exogenous progesterone during resynchronization starting on day 32 after the previous insemination will ameliorate the subsequent PR. In the same manner, Kawate et al. [37] stated that the CR of the cystic ovarian diseased cows subjected to CIDR-Ovsynch treatment regimen was $43.5 \%$. Nearly the same results were recorded previously by Bisinotto et al. [12] and Ahmed et al. [2] who reported that the CR following CIDR-Ovsynch protocol was $42.86 \%$ in postpartum anestrus crossbred cows. On the contrary, Ari et al. [6] reported that PR after CIDR-Ovsynch was 53\% in Brown-Swiss, Simmental, and crossbred cows which is higher than that observed in the current study for Simmental cows (34.92\%) subjected to the same protocol. Under the same Egyptian subtropical conditions, El-Zarkouny et al. [22] obtained higher PR at 29 days and 57 days (59.3\% and $45.1 \%$, respectively) in cows treated with CIDROvsynch compared with that recorded in the current study. The simplest explanation for this discrepancy might be due to the different breed, season of insemination, nutritional status of the cows, and dose of used drugs as well as the product of GnRH (Receptal vs Cystorelin) and statistical calculation methods of the reproductive parameters.

The ameliorative effect of CIDR-Ovsynch on the pregnancy outcomes in COD and anestrus diagnosed cows that treated with CIDR vaginal insert might be attributed to proper endocrine balance, progesterone priming, good body condition score (BCS) of the cows, and good managemental conditions [36]. Over and above, Rastegarnia and Anvari Savojbolghi [52] proposed that higher concentration of peripheral blood progesterone before insemination inhibits the secretion of PGF2 $\propto$ from the uterus. In addition, it is well recognized that the priming of reproductive system with appropriate amount of circulating progesterone during the preconception period is favorable for the better development of preovulatory follicle that will yield a well-developed CL and consequently successful conception occurs. Our results proposed that using CIDROvsynch protocol is useful in initiating cyclicity in subfertile cows, and it can be used as an efficient treatment tools for COD in dairy cows.

G6G presynchronization protocol depends on the idea that the first PGF2 $\propto$ injectionwill make luteolysis of all mature corpora lutea. Then, a GnRH injection 2 days late will encourage ovulation of mature follicles. So, the traditional Ovsynch protocol will be initiated at the sixth day of the cycle which is the ideal time as indicated by the augmented proportion of ovulated cows and the improved rate of synchronization [9]. In the current study, Simmental cows responded better to G6G protocol (48.98\%) than Holstein cows (34.57\%) with an overall PR of $36.69 \%$ (Table 2) which appeared lower than $50 \%$ recorded by Bello et al. [9] and also lower than CR (71.43\%) obtained by Ahmed et al. [2] following G6G treatments in postpartum anestrus crossbred cows. Meanwhile, it was greater than $(32.9 \%)$ that recorded by Heidari et al. [35] at 32 days post-insemination in 
submitted lactating Holstein cows reared in Iran. These conflict results might be attributed to the day of the estrous at which the treatment in initiated. Apart from variations might be attributed to different environmental, management, and genetic factors like nutritional status, parity, stage of lactation, suckling stimulus, season/ climate, drug source, age, breed, and species of animal.

Concerning the seasonal effect on the PR, the present investigation revealed high significant $(p<0.0001)$ seasonal effect with the higher PR obtained for cows bred during winter $(39.54 \%)$ as compared with that recorded cows bred during summer (29.18\%) as depicted in Tables 1 and table 2. During the cold season, the response of Simmental cows to PO (56.90\%) and G6G (54.41\%) was significantly $(p<0.01)$ higher than that recorded for Holstein herdmates (36.50\% and $38.10 \%$, respectively). This effect has not been observed during the hot season. The obtained PR during hot months in the current study is comparable to that recorded by Ahmadi and Ghaisari [1] for dairy cows in Iran (27.70\%) and more than that obtained by Ahuja et al. [3] in lactating anestrus crossbred cows (20.83\%), but less than that recorded by Alnimer et al. [5] in Friesian (56.30\%).Moreover, it has been stated that cows exposed to heat stress (HS) before breeding recorded significantly $(p<0.001)$ lower CR $(23 \%)$ compared to $31.3 \%$ that recorded for cows not exposed to HS [15]. The decreased PR observed for lactating cows inseminated during hot months may be ascribed to inadequate dry matter consumption resulting in poor BCS and consequently negative energy balance (NEB) that may lead to disturbances in secretion of hormones needed for reproduction [64], decreased fertilization rate, and a lowered proportion of zygotes reaching the blastocyst stage [33].

The harmful effect of HS before insemination is concomitant with a small diameter preovulatory follicles and inconstant biochemistry of the follicular fluid [57], which may lead to ovulation of poor-quality oocytes [24]. Hyperthermia of fertilized oocytes may inhibit embryonic growth [21]. Moreover, HS before breeding may result in delayed ovulation, anovulation, and ovulation of a poorquality oocyte, leading to diminished fertilization rate and high embryonic loss [4]. Furthermore, hyperthermia after breeding increased uterine temperature and diminished the uterine blood flow which may lead to failure of implantation and consequently increased early embryonic death [47]. All these detrimental effects are believed to be linked with reduced interferon-tau (signal to block CL regression) production by the conceptus [58]. Moreover, HS may disturb the secretions of prostaglandins and reduce the motility of the smooth muscle of the oviduct, which in turn disturb the transport of oocytes, spermatozoa, and zygote [40] which resulted in premature luteolysis of the corpus luteum graviditatis and consequently early death of the embryos [54]. Exposure of the uterus to high temperature may obstruct the endometrial factors essential for preservation of pregnancy.

Concerning the impact of cow's breed on the fertility results, assumptions are often made that some cattle breeds are significantly more fertile than others. Particular cattle breeds will entirely acclimate better to certain types of environmental conditions and have a higher fertility rate under those types of conditions. It has been reported that the heritability of reproductive measures in dairy cows is inferior when compared to other economically essential merits and the effects of environmental and managemental conditions are superior to the genetic merit [50]. The results of the current investigation revealed high significant ( $p=$ 0.003 ) effect of cow's breed on the PR (Table 1) as manifested by a higher PR recorded for Simmental cows $(45.16 \%)$ than that recorded for Holstein cows (34.98\%) as shown in Table 2. Furthermore, during the cold season, the responses of Simmental cows to PO (56.90\%) and G6G (54.41\%) were significantly $(p<0.01)$ greater than that of Holstein herdmates (36.50\% and $38.10 \%$, respectively). The results of the current study were concurred well with Piccand et al. [51] who found that Simmental cows recorded a high submission rate (86\%) and a high CR (89\%) and attributed these good results to the good BCS of this breed peripartum. Moreover, Toledo-Alvarado et al. [62] concluded that, the Simmental cows have a greater reproductive potential than Holstein cows. In addition, the crossbreed between Simmental and Holstein cows has been found to improve CR [34]. Equally, Knob et al. [39] informed that crossbred Simmental $\times$ Holstein cows had good reproductive efficacy compared with Holstein cows, characterized by higher CR (37.3 vs. $33.6 \%$ ). It has been well documented that there is a close relationship among BCS, NEB, and fertility [8]. NEB is recognized by the destruction of body fat reserve and ketone bodies and non-esterified fatty acids that exert a deleterious effect on both oocytes and corpus luteum functions. This results in low uterine progesterone concentration and hostile uterine conditions unsuitable for the embryonic development, leading to embryonic death [41]. Furthermore, it has been mentioned that, lactating cows which suffered from great BW loss in early lactation, entering in a state of greater NEB, had more reproductive problems than cows that lost less BW [60]. The lower PR of Holstein cows relative to that recorded previously for other breeds might be attributed to genetic improvement programs that have prioritized milking performance over other genetic predispositions. Interestingly, reproductive performance was closely associated with BCS; Simmental 
cows were the fattest and had the best results. Overall, a higher BCS post-calving was linked with increased reproductive performance, irrespective of breed.

\section{Conclusions}

Application of CIDR-Ovsynch breeding program could be used as an effective treatment regime for cystic ovarian disease in lactating dairy cows; likewise, G6G program could be used as a substitutional treatment regime for acyclic lactating cows. Furthermore, the present study would permit development of applicable breeding regimen to improve the fertility outcomes in intensive breeding commercial dairy farms.

\begin{abstract}
Abbreviations
BCS: Body Condition Score; CIDR: Controlled internal drug release device; COD: Cystic ovarian disease; CR: Conception rate; DIM: Days in milk; FTAI: Fixed-time artificial insemination; G6G: Gonadotropin releasing hormone of Presynch-6 days-gonadotropin releasing hormone of Ovsynch; GnRH: Gonadotropin releasing hormone; HS: Heat stress; NEB: Negative energy balance; Ovsynch: synchronization of ovulation; PGF2a: Prostaglandin F2 alpha; PO: Presynch-Ovsynch; PR: Pregnancy rater; Presynch: Presynchronization of ovulation
\end{abstract}

\section{Acknowledgements}

The author would like to sincerely thank Prof. Dr. Mahmoud Hussein for his kind help and support.

\section{Author's contribution}

The author designed the study, performed the statistical analysis, and drafted the manuscript. The author read and approved the final manuscript.

\section{Funding}

This study was achieved in a large private commercial dairy farm.

\section{Availability of data and materials}

The raw as well as the SPSS data are available.

\section{Ethics approval and consent to participate}

As this is a retrospective study depended mainly on data analysis, so we did not handle any cows at all.

\section{Consent for publication}

Not applicable.

\section{Competing interests}

The author declares that he has no competing interests.

Received: 3 July 2019 Accepted: 29 July 2019

Published online: 12 September 2019

\section{References}

1. Ahmadi MR, Ghaisari HR (2007) Heat stress and different timed-Al methods influence on pregnancy rates of dairy cows. VeterinarskiArhiv 77:327-335

2. Ahmed N, Doley S, Vanlalhriatpuia (2017) Inclusion of ovulation synchronization strategies for augmentation of fertility in post-partum anestrus crossbred cows. Int J Chem Stud 5:25-26

3. Ahuja C, Montiel F, Canseco R, Silva E, Mapes G (2005) Pregnancy rate following GnRH+PGF 2alpha treatment of low body condition, anestrous Bos taurus by Bos indicus crossbred cows during the summer months in a tropical environment. Anim Reprod Sci 87:203-213 Epub 2005 Jan 24. PubMed PMID: 15911171

4. Al-Katanani YM, Drost M, Monson RL, Rutledge JJ, Krininger CE 3rd, Block J, Thatcher WW, Hanse PJ (2002) Pregnancy rates following timed embryo transfer with fresh or vitrified in vitro produced embryos in lactating dairy cows under heat stress conditions. Theriogenology 58:171-182 PubMed PMID: 12182360
5. Alnimer M, De Rosa G, Grasso F, Napolitano F, Bordi A (2002) Effect of climate on the response to three oestrous synchronisation techniques in lactating dairy cows. Anim Reprod Sci 71:157-168 PubMed PMID: 12047925

6. Ari UC, Pancarci ȘM, Kaçar C, Güngör Ö, Lehimcioğlu NC, Öztürkler Y, Yıldız S (2017) Effect of progestagen application during Ovsynch protocol on pregnancy rates of lactating-grazing cows. Kafkas Univ Vet Fak Derg 23:319-324

7. Bamber RL, Shook GE, Wiltbank MC, Santos JE, Fricke PM (2009) Genetic parameters for anovulation and pregnancy loss in dairy cattle. J Dairy Sci 92: 5739-5753. https://doi.org/10.3168/jds.2009-2226

8. Bastin C, Loker S, Gengler N, Sewalem A, Miglior F (2010) Genetic relationships between body condition score and reproduction traits in Canadian Holstein and Ayrshire first-parity cows. J Dairy Sci 93:2215-2228. https:/doi.org/10.3168/ jds.2009-2720

9. Bello NM, Steibel JP, Pursley JR (2006) Optimizing ovulation to first GnRH improved outcomes to each hormonal injection of ovsynch in lactating dairy cows. J Dairy Sci 89:3413-3424 PubMed PMID: 16899674

10. Bhoraniya HL, Dhami AJ, Naikoo M, Parmar BC, Sarvaiya NP (2012) Effect of estrus synchronization protocols on plasma progesterone profile and fertility in postpartum anestrous Kankrej cows. Trop Anim Health Prod. 44: 1191-1197. https://doi.org/10.1007/s11250-011-0057-1

11. Bilby TR, Bruno RG, Lager KJ, Chebel RC, Moraes JG, Fricke PM, Lopes G Jr, Giordano JO, Santos JE, Lima FS, Stevenson JS, Pulley SL (2013) Supplemental progesterone and timing of resynchronization on pregnancy outcomes in lactating dairy cows. J Dairy Sci 96:7032-7042. https://doi.org/10.3168/jds.2013-6960

12. Bisinotto RS, Pansani MB, Castro LO, Narciso CD, Sinedino LD, Martinez $N$, Carneiro PE, Thatcher WW, Santos JE (2015) Effect of progesterone supplementation on fertility responses of lactating dairy cows with corpus luteum at the initiation of the Ovsynch protocol. Theriogenology 83: 257-265. https://doi.org/10.1016/j.theriogenology.2014.09.021

13. Bisinotto RS, Ribeiro ES, Santos JE (2014) Synchronisation of ovulation for management of reproduction in dairy cows. Animal 8:151-159. https://doi. org/10.1017/S1751731114000858

14. Cerri RL, Rutigliano HM, Chebel RC, Santos JE (2009) Period of dominance of the ovulatory follicle influences embryo quality in lactating dairy cows. Reproduction 137:813-823. https://doi.org/10.1530/REP-08-0242

15. Chebel RC, Santos JE, Reynolds JP, Cerri RL, Juchem SO, Overton M (2004) Factors affecting conception rate after artificial insemination and pregnancy loss in lactating dairy cows. Anim Reprod Sci 84:239-255 PubMed PMID: 15302368

16. Colazo MG, Ponce-Barajas P, Ambrose DJ (2013) Pregnancy per artificial insemination in lactating dairy cows subjected to 2 different intervals from presynchronization to initiation of Ovsynch protocol. J Dairy Sci 96: 7640-7648. https://doi.org/10.3168/jds.2013-6750

17. Dhami AJ, Nakrani BB, Hadiya KK, Patel JA, Shah RG (2015) Comparative efficacy of different estrus synchronization protocols on estrus induction response, fertility and plasma progesterone and biochemical profile in crossbred anestrus cows. Vet World 8:1310-1316. https://doi.org/10.14202/ vetworld.2015.1310-1316

18. Dirandeh E (2014) Starting Ovsynch protocol on day 6 of first postpartum estrous cycle increased fertility in dairy cows by affecting ovarian response during heat stress. Anim Reprod Sci 149:135-140. https://doi.org/10.1016/j. anireprosci.2014.07.018

19. Dirandeh E, Masoumi R, Didarkhah M, Samadian F, Davachi ND, Colazo MG (2018) Effect of presynchronization prior to Ovsynch on ovulatory response to first $\mathrm{GnRH}$, ovulatory follicle diameter and pregnancy per Al in multiparous Holstein cows during summer in Iran. Ann. Anim. Sci 18:713-722

20. Dirandeh E, Roodbari AR, Gholizadeh M, Deldar H, Masoumi R, Kazemifard M, Colazo MG (2015) Administration of prostaglandin F2a $14 \mathrm{~d}$ before initiating a G6G or a G7G timed artificial insemination protocol increased circulating progesterone prior to artificial insemination and reduced pregnancy loss in multiparous Holstein cows. J Dairy Sci 98:5414-5421. https://doi.org/10.3168/jds.2015-9417

21. Edwards JL, Bogart AN, Rispoli LA, Saxton AM, Schrick FN (2009) Developmental competence of bovine embryos from heat-stressed ova. J Dairy Sci 92:563-570. https://doi.org/10.3168/jds.2008-1495

22. El-Zarkouny SZ, Cartmill JA, Hensley BA, Stevenson JS (2004) Pregnancy in dairy cows after synchronized ovulation regimens with or without presynchronization and progesterone. J Dairy Sci 87:1024-1037 PubMed PMID: 15259238

23. Ferguson JD, Skidmore A (2013) Reproductive performance in a select sample of dairy herds. J Dairy Sci 96:1269-1289. https://doi.org/10.3168/ jds.2012-5805 
24. Ferreira RM, Ayres $H$, Chiaratti MR, Ferraz ML, Araújo $A B$, Rodrigues $C A$, Watanabe YF, Vireque AA, Joaquim DC, Smith LC, Meirelles FV, Baruselli PS (2011) The low fertility of repeat-breeder cows during summer heat stress is related to a low oocyte competence to develop into blastocysts. J Dairy Sci 94:2383-2392. https://doi.org/10.3168/jds.2010-3904

25. Fricke PM, Giordano JO, Valenza A, Lopes GJ, Amundson MC, Carvalho PD (2014) Reproductive performance of lactating dairy cows managed for first service using timed artificial insemination with or without detection of estrus using an activity-monitoring system. J Dairy Sci 97:2771-2781. https:// doi.org/10.3168/jds.2013-7366

26. Galvão KN, Santos JE (2010) Factors affecting synchronization and conception rate after the Ovsynch protocol in lactating Holstein cows. Reprod Domest Anim 45:439-446. https://doi.org/10.1111/j.1439-0531.2008.01220.x

27. Galvão KN, Santos JE, Cerri RL, Chebel RC, Rutigliano HM, Bruno RG, Bicalho RC (2007) Evaluation of methods of resynchronization for insemination in cows of unknown pregnancy status. J Dairy Sci 90:4240-4252 PubMed PMID:17699043

28. Giordano JO, Fricke PM, Cabrera VE (2013) Economics of resynchronization strategies including chemical tests to identify nonpregnant cows. J Dairy Sci 96:949-961. https://doi.org/10.3168/jds.2012-5704

29. Giordano JO, Fricke PM, Guenther JN, Lopes GJ, Herlihy MM, Nascimento AB, Wiltbank MC (2012b) Effect of progesterone on magnitude of the luteinizing hormone surge induced by two different doses of gonadotropin-releasing hormone in lactating dairy cows. J Dairy Sci 95: 3781-3793. https://doi.org/10.3168/jds.2011-5155

30. Giordano JO, Kalantari AS, Fricke PM, Wiltbank MC, Cabrera VE (2012a) A daily herd Markov-chain model to study the reproductive and economic impact of reproductive programs combining timed artificial insemination and estrus detection. J Dairy Sci 95:5442-5460. https://doi.org/10.3168/jds.2011-4972

31. Giordano JO, Stangaferro ML, Wijma R, Chandler WC, Watters RD (2015) Reproductive performance of dairy cows managed with a program aimed at increasing insemination of cows in estrus based on increased physical activity and fertility of timed artificial inseminations. J Dairy Sci 98:2488-2501. https:// doi.org/10.3168/jds.2014-8961

32. Giordano JO, Wiltbank MC, Guenther JN, Pawlisch R, Bas S, Cunha AP, Fricke PM (2012c) Increased fertility in lactating dairy cows resynchronized with Double-Ovsynch compared with Ovsynch initiated $32 \mathrm{~d}$ after timed artificial insemination. J Dairy Sci 95:639-653. https://doi.org/10.3168/jds.2011-4418

33. Hackbart KS, Ferreira RM, Dietsche AA, Socha MT, Shaver RD, Wiltbank MC, Fricke PM (2010) Effect of dietary organic zinc, manganese, copper, and cobalt supplementation on milk production, follicular growth, embryo quality, and tissue mineral concentrations in dairy cows. J Anim Sci 88:3856-3870. https://doi.org/10.2527/jas.2010-3055

34. Hazel AR, Heins BJ, Seykora AJ, Hansen LB (2014) Production, fertility, survival, and body measurements of Montbéliarde-sired crossbreds compared with pure Holsteins during their first 5 lactations. J Dairy Sci 97: 2512-2525. https://doi.org/10.3168/jds.2013-7063

35. Heidari F, Dirandeh E, Ansari Pirsaraei Z, Colazo MG (2017) Modifications of the G6G timed-Al protocol improved pregnancy per Al and reduced pregnancy loss in lactating dairy cows. Animal 11:2002-2009. https://doi. org/10.1017/S1751731117000520

36. Kawate N, Itami T, Choushi T, Saitoh T, Wada T, Matsuoka K, Uenaka K, Tanaka N, Yamanaka A, Sakase M, Tamada H, Inaba T, Sawada T (2004) Improved conception in timed-artificial insemination using a progesterone-releasing intravaginal device and Ovsynch protocol in postpartum suckled Japanese Black beef cows. Theriogenology 61:399-406 PubMed PMID: 14662139

37. Kawate N, Watanabe K, Uenaka K, Takahashi M, Inaba T, Tamada H (2011) Comparison of plasma concentrations of estradiol-17 $\beta$ and progesterone, and conception in dairy cows with cystic ovarian diseases between Ovsynch and Ovsynch plus CIDR timed Al protocols. J Reprod Dev 57: 267-272 Epub 2011 Jan 14. PubMed PMID:21242655

38. Kim IH, Suh $\mathrm{GH}$, Son DS (2003) A progesterone-based timed Al protocol more effectively prevents premature estrus and incomplete luteal regression than an Ovsynch protocol in lactating Holstein cows. Theriogenology 60:809-817 PubMed PMID: 12935859

39. Knob DA, Alessio DR, Thaler Neto A, Mozzaquatro FD (2016) Reproductive performance and survival of Holstein and Holstein $\times$ Simmental crossbred cows. Trop Anim Health Prod 48:1409-1413. https://doi.org/10.1007/s11250-016-1103-9

40. Kobayashi Y, Wakamiya K, Kohka M, Yamamoto Y, Okuda K (2013) Summer heat stress affects prostaglandin synthesis in the bovine oviduct. Reproduction 146:103-110. https://doi.org/10.1530/REP-12-0479
41. Leroy JL, Opsomer G, Van Soom A, Goovaerts IG, Bols PE (2008) Reduced fertility in high-yielding dairy cows: are the oocyte and embryo in danger? Part I. The importance of negative energy balance and altered corpus luteum function to the reduction of oocyte and embryo quality in high-yielding dairy cows. Reprod Domest Anim 43:612-622. https://doi.org/10.1111/j.1439-0531.2 007.00960.x

42. Lima JR, Rivera FA, Narciso CD, Oliveira R, Chebel RC, Santos JE (2009) Effect of increasing amounts of supplemental progesterone in a timed artificial insemination protocol on fertility of lactating dairy cows. J Dairy Sci 92: 5436-5446. https://doi.org/10.3168/jds.2009-2134

43. Lucy MC, Billings HJ, Butler WR, Ehnis LR, Fields MJ, Kesler DJ, Kinder JE, Mattos RC, Short RE, Thatcher WW, Wettemann RP, Yelich JV, Hafs HD (2001) Efficacy of an intravaginal progesterone insert and an injection of PGF2alpha for synchronizing estrus and shortening the interval to pregnancy in postpartum beef cows, peripubertal beef heifers, and dairy heifers. J Anim Sci 79:982-995 PubMed PMID: 11325206

44. Miller RH, Norman HD, Kuhn MT, Clay JS, Hutchison JL (2007) Voluntary waiting period and adoption of synchronized breeding in dairy herd improvement herds. J Dairy Sci 90:1594-1606 PubMed PMID: 17297133

45. Moreira F, de la Sota RL, Diaz T, Thatcher WW (2000) Effect of day of the estrous cycle at the initiation of a timed artificial insemination protocol on reproductive responses in dairy heifers. J Anim Sci 78:1568-1576 PubMed PMID: 10875641

46. Moreira F, Orlandi C, Risco CA, Mattos R, Lopes F, Thatcher WW (2001) Effects of resynchronization and bovine somatotropin on pregnancy rates to a timed artificial insemination protocol in lactating dairy cows. J Dairy Sci 84:1646-1659 PubMed PMID:11467815

47. Morton JM, Tranter WP, Mayer DG, Jonsson NN (2007) Effects of environmental heat on conception rates in lactating dairy cows: critical periods of exposure. J Dairy Sci 90:2271-2278 PubMed PMID: 17430927

48. Motavalli T, Dirandeh E, Deldar H, Colazo MG (2017) Evaluation of shortened timed-Al protocols for resynchronization of ovulation in multiparous Holstein dairy cows. Theriogenology 95:187-192. https://doi.org/10.1016/j. theriogenology.2017.03.003

49. NRC (2001) Nutrient requirements of dairy cattle. 7th rev. ed. National Academic Science, Washing-ton, DC

50. Pantelić V, Sretenovic L, Ostojic-Andric D, Trivunovic S, Petrovic MM, Aleksic S, Ruzic-Muslic D (2011) Heritability and genetic correlation of production and reproduction traits of Simmental cows. Afr. J. Biotechnol. 10:7117e7121

51. Piccand V, Cutullic E, Meier S, Schori F, Kunz PL, Roche JR, Thomet P (2013) Production and reproduction of Fleckvieh, Brown Swiss, and 2 strains of Holstein-Friesian cows in a pasture-based, seasonal-calving dairy system. J Dairy Sci 96:5352-5363. https://doi.org/10.3168/jds.2012-6444

52. Rastegarnia AAR, Anvari Savojbolghi H (2010) Effect of CIDR-based (CIDRSynch) protocol, for timed artificial inseminations, and on the conception rate of dairy cows. J Vet Clin Res Fall. 1:243-252

53. Rivera $\mathrm{H}$, Lopez H, Fricke PM (2005) Use of intravaginal progesterone-releasing inserts in a synchronization protocol before timed Al and for synchronizing return to estrus in Holstein heifers. J Dairy Sci 88:957-968 PubMed PMID: 15738230

54. Santolaria P, López-Gatius F, García-Ispierto I, Bech-Sàbat G, Angulo E, Carretero T, Sánchez-Nadal JA, Yániz J (2010) Effects of cumulative stressful and acute variation episodes of farm climate conditions on late embryo/ early fetal loss in high producing dairy cows. Int J Biometeorol 54:93-98. https://doi.org/10.1007/s00484-009-0258-8

55. Santos JE, Narciso CD, Rivera F, Thatcher WW, Chebel RC (2010) Effect of reducing the period of follicle dominance in a timed artificial insemination protocol on reproduction of dairy cows. J Dairy Sci 93:2976-2988. https:// doi.org/10.3168/jds.2009-2870

56. Schefers JM, Weigel KA, Rawson CL, Zwald NR, Cook NB (2010) Management practices associated with conception rate and service rate of lactating Holstein cows in large, commercial dairy herds. J Dairy Sci 93:1459-1467. https://doi. org/10.3168/jds.2009-2015

57. Shehab-El-Deen MA, Leroy JL, Fadel MS, Saleh SY, Maes D, Van Soom A (2010) Biochemical changes in the follicular fluid of the dominant follicle of high producing dairy cows exposed to heat stress early post-partum. Anim Reprod Sci 117:189-200. https://doi.org/10.1016/j.anireprosci.2009.04.013

58. Shirasuna $K$, Matsumoto $H$, Matsuyama S, Kimura K, Bollwein H, Miyamoto A (2015) Possible role of interferon tau on the bovine corpus luteum and neutrophils during the early pregnancy. Reproduction 150:217-225. https:// doi.org/10.1530/REP-15-0085 
59. Silva E, Sterry RA, Kolb D, Wiltbank MC, Fricke PM (2007) Effect of pretreatment with prostaglandin F2alpha before resynchronization of ovulation on fertility of lactating dairy cows. J Dairy Sci 90:5509-5517 PubMed PMID:18024742

60. Snijders SE, Dillon PG, O'Farrell K, Diskin M, Wylie AR, O'Callaghan D, Rath M, Boland MP (2001) Genetic merit for milk production and reproductive success in dairy cows. Anim Reprod Sci 65:17-31 PubMed PMID: 11182505

61. Stevenson JS (2016) Synchronization and artificial insemination strategies in dairy herds. Vet Clin North Am Food Anim Pract 32:349-364. https://doi. org/10.1016/j.cvfa.2016.01.007

62. Toledo-Alvarado H, Cecchinato A, Bittante G (2017) Fertility traits of Holstein, Brown Swiss, Simmental, and Alpine Grey cows are differently affected by herd productivity and milk yield of individual cows. J Dairy Sci 100:82208231. https://doi.org/10.3168/jds.2016-12442

63. Wheaton JE, Lamb GC (2007) Induction of cyclicity in postpartum anestrous beef cows using progesterone, GnRH and estradiol cypionate (ECP). Anim Reprod Sci 102:208-216 Epub 2006 Nov 19. PubMed PMID: 17169514

64. Wheelock JB, Rhoads RP, Vanbaale MJ, Sanders SR (2010) Baumgard LH (2010) Effects of heat stress on energetic metabolism in lactating Holstein cows. J Dairy Sci. 93:644-655. https://doi.org/10.3168/jds.2009-2295

65. Wiltbank MC, Pursley JR (2014) The cow as an induced ovulator: timed Al after synchronization of ovulation. Theriogenology. 81(1):170-185. https:// doi.org/10.1016/j.theriogenology.2013.09.017

\section{Publisher's Note}

Springer Nature remains neutral with regard to jurisdictional claims in published maps and institutional affiliations.

\section{Submit your manuscript to a SpringerOpen ${ }^{\circ}$ journal and benefit from:}

- Convenient online submission

- Rigorous peer review

- Open access: articles freely available online

- High visibility within the field

- Retaining the copyright to your article 